\title{
A resocialization intervention model in the prison - the family: people helping people project
}

\begin{abstract}
The Bahamas is suffering from a serious social fragmentation process, due to the cocaine crisis of the 1980's and its continuing sequelae. Burgeoning murder and violent crime rates associated with family and community disintegration have led to the incarceration of many young persons. The Family: People Helping People Project is a community based intervention designed to confront social fragmentation and promote re-socialization among the inmates at the Bahamas Department of Corrections. The method used is a dynamic supportive group process, involving storytelling, personal reflection and transformation based on the psychotherapeutic principles of the Contemplative Discovery Pathway Theory (CDPT). Since the program's inception, there have been 109 group sessions. A thematic analysis of these sessions indicates the four most common themes were violence, anger, revenge and addiction. The thematic analysis of the Prison group, described in this paper indicates the depths of negativity of shame but also provides hope for Resocialization and preparation for the inmates to live a meaningful and crime-free community life upon their release. This paper discusses the Resocialization process of a group of inmates who attended the program for three (3) years.
\end{abstract}

Keywords: social fragmentation, incarceration, resocialization, freedom, anger, prison, gratitude questionnaire six item form, internalized shame scale, spiritual well being scale, satisfaction with life scale, contemplative discovery pathway theory
Volume I Issue 4 - 2017

\author{
David F Allen,' Maria Flavia D Alessandro,' \\ Keva Bethell ${ }^{3}$ \\ 'Department of Psychiatry and Public Health, Harvard \\ University, USA \\ 2Department of Psychiatry, Bahamas Historical Society, Bahamas \\ ${ }^{3}$ Department of Public Health, Allen Institute of Research and \\ Training, Bahamas
}

Correspondence: David F Allen, Department of Psychiatry and Public Health, Harvard University, USA,

Email dfallen43@gmail.com

Received: August 15, 2017 | Published: October 16, 2017

\section{Introduction}

The Bahamas, like many other countries in the Caribbean and South Americans facing a serious social fragmentation process related to the widespread cocaine epidemic of the 1980s and its continuing sequelae of drug trafficking and violence due to an excessive supply of guns and the high unemployment rate relating to the recent international financial downturn. ${ }^{1}$ Involving family and community disintegration, the social fragmentation has spurned a culture of violence with burgeoning murder and violent crime rates, domestic violence, violent youth gangs and different types of abuse. ${ }^{2}$

\section{The family}

People Helping People Project was initiated by Dr. David Allen to provide a space for mothers who had lost their sons to murder to help them work through their grief. These meetings were eventually forged into support groups and later developed into the Family: People Helping People Project. This project is a community based intervention designed to confront social fragmentation and promote resocialization. American Sociologist Erving Goffman coined the phrase 'community resocialization' and described it as the deconstruction and reconstruction of one's values, abilities and beliefs. ${ }^{3}$ The program is offered in 24 marginalized Bahamian communities and select populations, including a group for inmates at the Bahamas Department of Corrections (Her Majesty's Prison). In the context of 'The Family Prison group' the resocialization intervention is offered in two stages involving an 18 month pre-release group during incarceration and an after release group when ex-inmates are strongly encouraged to be part of the community Family program.

Persons are encouraged to share their stories in a contemplative environment of love, silence and non-judgmental listening creating a powerful healing bond which we define as "Family". In both the community populations and the program at the prison, resocialization is developed through a dynamic supportive group process, involving storytelling, personal reflection and transformation based on the psychotherapeutic principles of the Contemplative Discovery Pathway Theory (CDPT) ${ }^{4}$ The Family project attempts to redefine the complex concept of resocialization through the collaboration between both societal group settings involving closed institution groups and open community groups. The Family has hosted 109 group sessions at the Prison since its inception in April 2014.

The incarceration conditions at The Bahamas Department of Corrections (also known as Her Majesty's Prison) are challenging with an overcrowding rate of $72.7 \%$. Built to house a maximum capacity of 1000 prisoners, the Prison's population in October 2016 was 1727 prisoners. According to World Prison Brief of the University of London, the Bahamian prison population rate is 439 per 100,000 persons. The Bahamian rate is more than three times the world average and higher than the Caribbean rate of 347 per $100,000 .^{5}$

\section{The family prison group}

The purpose of this article is to describe the challenges of establishing a Family group in the Prison and to discuss the qualitative analysis of the various themes presented by the inmates. Our hope is that the qualitative analysis along with the testimonial data will provide a clearer understanding of the challenges of resocialization in the prison population. The Family offers a weekly group meeting at the prison lasting 90 minutes and is attended by 20 to 25 inmates. Initially, there were about three female inmates in the group. However, they were withdrawn by the authorities and we eventually became an all-male group. Most of the inmates are part of a pre-release program and are expected to leave the prison in 18 months. However, a few of 
the inmates in the group are facing life sentences. We are allowed to set the guidelines, but the inmates are selected by the prison officers. In the development of the group, we stress the importance of three (3) major principles:

i. Confidentiality: inmates are encouraged to leave what is discussed at the group meeting and only express how they were affected after the group. This encourages trust and helps the inmate to face their problems and work toward their solutions.

ii. Non-judgmental approach: We encourage a strong nonjudgmental approach to enhance respect for persons sharing their personal and painful stories.

iii. Free expression: each person is given the time and space to share their story.

The group is conducted by three (3) facilitators. After each session, a praxis report is written by one of the facilitators. This praxis includes a description of the interactions, a list of the themes and a short reflection about the session. The themes are then analyzed by a researcher and the incidence of the most prominent themes is coded in a thematic analysis.

\section{The allen resocialization scale}

The Family Project is research-based. Participants are required to undergo psychological testing every six months to document their progress in the program. The participants were tested in two cohorts. Participants who were a part of cohort one were required to fill out a background questionnaire and a test battery that included nine psychological test scales, namely the Beck Depression Inventory, Buss-Durkee Hostility-Guilt Inventory, Gratitude Questionnaire-SixItem Form (GQ-6), The Hope Scale, Self-Deception Questionnaire, Internalized Shame Scale (ISS), the Spiritual Well-Being Scale (SWBS), Satisfaction with Life Scale (SWLS) and the TransgressionRelated Interpersonal Motivations Inventory-18-Item Version (TRIM18). Participants who were part of cohort 2 were required to fill out a background questionnaire and the Allen Resocialization Scale.

The Allen Resocialization Scale was created by conducting a thorough literature review of current accepted scales of rehabilitation and wellness. Forty-one (41) evaluation questions were selected from established questionnaires that have been used to measure different aspects of well-being as it relates to Resocialization. These include items assessing the management of emotions, alexithymia (feeling awareness), resilience and outlook on life. Other elements measured include shame, suicidal ideation, satisfaction with life and depression. Responses were standardized to a Likert-type scale, ranging from 1='Strongly disagree,' 2='Disagree,' $3=$ ='Neither agree nor disagree,' 4='Agree,' and 5='Strongly agree'. Participant responses were tallied at the end to form a comprehensive score. The inmates were part of cohort 2. Results from the Allen Scale indicate increases in positive emotions such as well-being, spirituality, awareness, forgiveness and stress management. Decreases in family bonds were reported, however, additional testing is required to prove significance in this area. ${ }^{6}$ The inmates' responses to their changes in anger and revenge since participating in the Family program indicate the program's success in re-socializing its participants. It is interesting that even though there has been a decrease in thoughts of violent revenge, there seems to be an increase in non-violent revengeful thoughts (Figure 1). We believe this is because the inmates need more time to work through their deep hurt and shame.

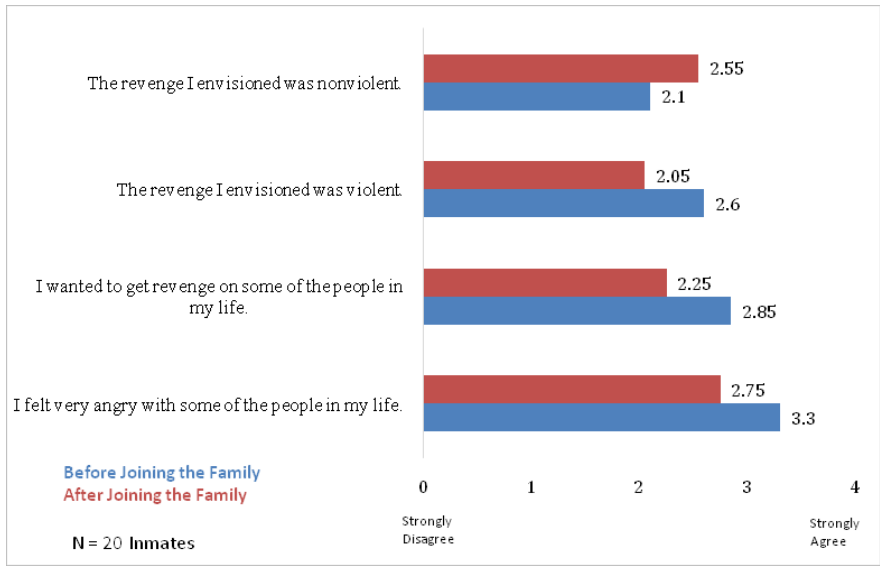

Figure I Self-Reported Differences in Anger and Revenge.

\section{Development of group cohesion}

As the group members shared their stories, a sense of belonging and empowerment developed. Endeavoring to have ownership of the group, the inmates named the group the 'Free Your Mind Group' because this was the only space where they had a chance to express their feelings freely. The group members wanted to punish those who disobeyed the requirements but we agreed to a compromise that persons not complying would be suspended for a period and reinstated. Eventually, when the men became aware that they were angry and agitated, they excused themselves and returned when they felt ready to do so.

Anger was the most prominent theme in the group and we chose to work through it by exploring the underlying fears and hurts involved. We found that using the metaphor of seeing anger as a siren on an ambulance was very helpful. Thus, when anger occurred in the group, it alerted us that the person was hurting deeply and he needed our support. Another initiative which was helpful in making the group their own was the institution of a "graduation ceremony". We agreed to this and every June, they receive a certificate of participation with their names on it. This ceremony is appreciated deeply and they show their gratitude through songs, poetry, speeches and small gifts. For some, this was the first certificate they ever received and it meant a lot to them.

We also found that stories and myths were an excellent way of connecting with them. For example, they particularly liked the Slave Myth. In this ancient myth, a slave was captured and chained to a stake. He walked around the stake, looking out at the distant mountains and dreaming of being free to start a new life. Then looking at his chain, he realized that he was trapped and freedom was impossible. The myth continues that one night an angel broke the chain. When the slave awoke the next morning, he was shocked to find his chain broken. Getting up, he ran toward the mountains hoping to take advantage of his new found freedom. But then he started to fear the unknown. Looking back at his broken chain, his pain, he was caught in the dilemma of running to his freedom or returning to the prison of the familiar. After much hesitation, he returned, picked up his broken chain and walked around the stake the rest of his life. Although the external chains were broken, the internal chains around his heart were still intact.

This story had a powerful effect on the group and initiated a discussion about physical and mental freedom. They realized that one 
can be physically free but still mentally imprisoned or vice versa. True freedom is not only breaking the external chains, but more importantly, breaking the chains around our heart. They cited lyrics from Bob Marley's "Redemption Song", 'emancipate yourselves from mental slavery, none but ourselves can free our minds' Throughout our group sessions "The Slave Myth" has been discussed repeatedly. We stressed that although we were aware that they were living in a real prison "made of concrete", the Family's mission was to liberate them from their "internal chains", and help them to realize the potential of their inner life. Victor Frankl, who lived in a concentration camp, describes this when he says, "Everything can be taken from a man but one thing: the last of the human freedoms to choose one's attitude in any given set of circumstances, to choose one's own way". ${ }^{7}$ The inmates claim they share the information gained from their group with their families and friends. This is important because this expands the resocialization work beyond the prison walls.

The development of trust is central to the group. Initially, they were curious and were not sure what to expect. In the first months of our group meetings, group members tested our commitment by "pushing the boundaries" (e.g. accusations, provocation, fighting, shaming), trying to use us for personal gain (money, gifts or sending messages to friends and family) or rebelling against the rules. However, our commitment to stability, consistency and predictability engendered trust. But they were still skeptical (e.g. they accused us of working for an American Intelligence Agency and spying on them). To counteract this distrust, we were fortunate to have on our team Mr. André Chappelle, a recovered drug addict who had been imprisoned five times. The inmates made it very clear that they knew him and trusted him. But it would take time for them to trust us. Mr. Chappelle was a catalyst for hope and change. In fact, the miracle of his transformation from a homeless drug addict and criminal to a knowledgeable cofacilitator in the group was a powerful statement. Many of the men recognized him from the streets and became emotional when they realized the transformation of his life. They told him, 'you give us hope. If you can change your life, we can also'. Mr. Chappelle initiated the first "Prison Arts and Crafts Show" which was a great success. The public was very impressed, particularly with how well the inmates conducted themselves.

Sadly, Mr. Chappelle was diagnosed with cancer and died within six months. This had a major impact on the group forcing them to face their feelings of grief. Painful as it was, this introduced a deeper dimension to the group. The men were very moved and expressed their sadness openly by crying and reflecting on their own lives. In a strange way, Mr. Chappelle's life, illness and death enhanced the resocialization process of the group.

\section{The role of shame}

Shame is a powerful multi-faceted emotion which results from the shattering or loss of cherished expectations, wishes or dreams, creating in us the sense of abandonment, rejection and humiliation. ${ }^{8}$ Though hidden and attached to our deepest, personal secrets, the faces of shame are seen in society as anger, violence, revenge and abuse. As a result, the person becomes at war with themselves so that shame may be defined as Self Hatred Aimed at ME. Social fragmentation results when a person becomes a victim of the negativity of shame, giving them a diminished view of themselves, others and the world. Conversely, re-socialization is the liberation from the negativity of shame to experience the positive emotions of love, forgiveness and gratitude, resulting in increased self-esteem and the development of meaningful community. Our hope is that by analyzing the overt themes of 'The Family Prison Group', we would have a better understanding of the predominant issues of shame in the inmates and have the opportunity to confront and work through them.

The Family group process is based on the Contemplative Discovery Pathway Theory (CDPT). This is a psychodynamic theory that integrates psychopathology, positive emotions and contemplative spirituality. It is a developmental model that postulates that the Self follows a stepwise path from the Natural Self at birth to The Shame False Self, to the healthier Authentic Gracious Self in adulthood and potentially even the Contemplative Transcendent Self later in life. ' As described earlier, the term 'Family' is defined as the bond created by the sharing of our authentic stories in an environment of love, acceptance and non-judgmental listening. As the group shares their stories of shame and pain, they destroy their defensive Shame False Self, based in fear and anger and move towards their Authentic Selves based in love and gratitude. Thus, the group experience is the healing agent and the role of the facilitators is to remove or reduce the obstacles to the healing process. This is done by:

i. Positively reinforcing healing behaviors and insights (offering conditions for safety, connection and empowerment).

ii. Kindly but firmly redirecting behaviors that are considered obstacles to healing (abandonment, rejection and humiliation).

iii. Role-modeling behavior: resocialization through an experience of love, forgiveness, humility and gratitude.

The Family group process is open and dynamic. New inmates are welcomed to join once approved by the officers. Each group session involves the following components:

\section{The stillness meditation exercise}

All our sessions begin with a stillness meditation exercise based on breathing techniques and visualization exercises using the color blue. This exercise is very meaningful to the inmates. Many of the men were raised on the ocean and were used to seeing the deep blue sea. In prison, this is not possible, so they replace the sea by observing the blue sky. The exercise is also appreciated because the inmates claim it helps them to relax. Even though their accommodations are limited and crowded, they practice the stillness exercise in their cells, which brings peace and relaxation to them. The stillness exercise ends with a prayer of gratitude. The goal of this exercise is explained to the group every session. We explain that the exercise is used to prepare our mind to be more aware and attentive. According to David Foster Wallace: "Learning how to think really means learning how to exercise some control over how and what you think. It means being conscious and aware enough to choose what you pay attention to and to choose how you construct meaning from experience think of the old cliché about 'the mind being an excellent servant but a terrible master"'. ${ }^{10}$

\section{Open group discussion}

The stillness exercise is followed by 60 -minute open group discussion where the inmates share stories of their lives and relate to national and international events. Often, handouts are given to enhance the discussion using quotes from persons like Nelson Mandela, Viktor Frankl and Maya Angelou. The group found that using the metaphor of our heart being like a sponge was very helpful. Like a sponge, the heart absorbs the love as well as the hurt and shame. Sadly, as the sponge becomes full of hurt and shame, it makes it difficult to receive 
or give love. The goal of the Family group in Prison is to squeeze the sponge to release the hurt and shame from our heart and allow love to increase self-esteem and create caring community. Group members alternate in sharing their stories and the facilitators' role is to assure the flow of the group process. Role-playing and centering techniques enhance sharing and healing. As persons get in contact and release their shame, a powerful catharsis results. This is a time for silence, understanding and non-judgmental listening.

\section{Ending a session}

The last 15 minutes are used to summarize the main issues of a session. Usually, an inspiring story is told to illustrate principles expressed during the meeting. Closure is established when the session ends with a song, poetry and a closing prayer.

\section{Discussion}

In The Family Prison Group, the four most common themes are violence, anger, revenge and addiction. In 109 group sessions those themes appeared 80 times (Figure 2). Group participants indicate that anger is perceived by them as the fuel for violence. Revenge is the most common justification for violence and addiction is used as their coping mechanism. Violence has been at the center of their lives from childhood to present. It was at home (e.g. beating of children, fights between siblings, gender based violence), in the communities (e.g. killings for gang rivalry, punishment for stealing, revenge motivated violence) and now in the prison (e.g. poor conditions and fighting). Although constantly describing violence in the group, the group participants never use the term 'violence'. They do not see it as a problem, but as a normal component of their lives.

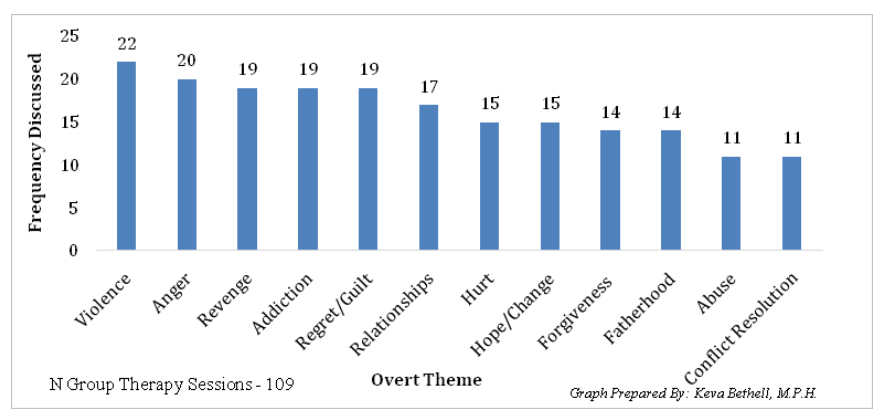

Figure 2 Thematic Analysis of Family Sessions at Her Majesty's Prison.

Anger is perceived as a natural response to an attack but it may be toxic, uncontrollable and destructive. According to one of the inmates, 'when you kill for the first time you feel sick and can't stop thinking about it. You feel like you're going crazy. After a while you get used to it, get drunk and high, and you feel numb'. Anger and revenge are intimately linked. A knowledgeable inmate said his impression was that 'at least $45 \%$ of murders involve revenge'. Sadly, revenge is perceived as 'an act of love'. In a society with minimal trust in social justice, revenge abounds. According to the inmates, there are only two counter arguments to the idea of revenge as love:

i. If caught and punished by society for a revengeful act, it will make your loved ones suffer and

ii. If one is religious, God is responsible for vengeance and not us. But they admit that revenge is natural or instinctive. Forgiveness is difficult and requires a lot of growth and development to think that way.

\section{Case vignettes}

Here are some excerpts from the group process dealing with the four most prevalent themes of volatility (violence), anger, revenge and addiction:

\section{An example of emotional volatility (violence) in the group}

A group member confronted another member saying, "I am waiting for you to apologize to me!" Responding, the accused person jumped up, ready to fight the accuser. Suddenly, the other inmates jumped up and stood between them to prevent a fight. The officer on duty immediately intervened, taking both men out of the room to cool down. The facilitators told the officers that they wanted the men to return to the group as soon as they were willing to continue talking and not fight. While they were gone, the inmates expressed their annoyance with the accuser who they claimed was explosive and destructive. Other members were shocked at the escalation of the altercation. The facilitators encouraged the group to work it through by sharing their feelings. Many shared and agreed that even though the accuser was a trouble maker, the accused did not have to react so aggressively. Eventually, they started to plan how to help both men overcome the situation. They shared such ideas like, "let them cool down for a couple of days and then we will talk with them.

The accuser came back smiling. The officer explained to the group that the accused was still very angry and would return to the group the following week. The accuser explained in detail the problem he had with the accused. The group's annoyance was palpable and tensions started to rise again. The facilitators reminded the group that we just had an amazing opportunity to learn about anger. They asked each member of the group to share how the experience affected them. Sharing their feelings, the members calmed down and some even became humorous to diffuse the atmosphere. The men shared that growth is difficult and requires patience and understanding. One person said he has to grow and soon leave prison because his two daughters, whom he loves deeply, are waiting for him.

\section{An example of how anger manifests in group process}

Another example of how the group process diverts anger is the following group interaction: 'A participant tells the group he is not sure if he can practice meditation by himself because he fears "going crazy". Explaining, he said "my mind is in deep struggle. I want to walk away from conflict but it is hard not to keep thinking of revenge". He shared with the group how other inmates are constantly provoking him, e.g. stealing his property, not respecting his personal space and making jeers at him. He said this last Sunday, he was very provoked and could have reacted violently. He said if this had happened on the outside, he would have killed in a heartbeat. But taking time to think it over, he said he kept imagining the facilitators asking about him. He could hear the group members saying "He can no longer come. $\mathrm{He}$ is in maximum security prison now because he got in trouble". Continuing, he said, "I remember you (facilitators) asking about two other participants who were no longer in the group. I can't disappoint the group. I am here to ask for help because I find it hard to let go of revenge from my mind!”

Mocking him, two group members reacted sarcastically, "You don't want to let go of revenge because you really want to kill. You are not ready to change". Realizing the developing conflict, the facilitators 
intervened immediately, reframing the discussion by reminding the group that everyone has the right to express themselves freely.

Another participant shared: "I understand you. I feel the same, but after coming to this group and learning about revenge, I have been out of trouble for one year now. I know it is hard but you must walk away. We don't want to stay in this place forever".

\section{An example of how revenge manifests in group process}

A member of the group said he disagreed with the statement 'you should destroy evil by destroying the evildoer'. He said "I have done evil and they have destroyed me by putting me in prison. I want everyone to be treated like me. I want all evildoers killed'. The group challenged him that evil could happen to anyone. Destroying all evildoers would mean no one would be left.

Recognizing that the group members disagreed with him in a respectful and accepting manner, he continued to talk about his hurt and anger. Describing the depth of his anger, he said, 'I hate people. I can't trust them because they hurt me badly. My mother abandoned me at eight years old, went to the U.S. and had another family. My father also abandoned me and my grandmother raised me, but the rest of the family members and neighbors scorned me. My daughter is my only love but sadly I've abandoned her and I hate myself because I've done to her what was done to me.'. Obviously, the gentleman was becoming aware of his hate for himself, that is, his shame (Self Hatred Aimed at M.E.). He recognized the repetition compulsion where he abandoned his daughter like everybody else abandoned him. Sharing this had a powerful effect on him. He confessed to the group that sharing like this is unusual for him and he was surprised that he was able to do it.

\section{An example of how addiction manifests in group process}

By far, the preferred drug of choice is cannabis. Group members often describe their 'love for weed'. They use it to calm down and avoid violent outbursts. They said that when they are rewarded with cigarettes for performing chores, they find it easy to obtain cannabis and put it in their cigarettes.

Alcohol is synonymous with celebration, e.g. a birthday party with friends and getting drunk together. But some of the men shared that they were deeply hurt by alcoholic parents. One gentleman said, 'I got tired of seeing my parents drink and fight. I became curious about the bottle they liked so much. I was eight years old when I got drunk for the first time. I wanted to feel what my parents were feeling'. The inmates agreed that the time spent in prison was an excellent opportunity to work on themselves and become sober. The men not only discussed addiction to drugs and alcohol, but also described being addicted to guns, sex, power and money. One inmate admitted 'I am using this time to think about my life. Greed brought me here. I had a job, but it was never good enough. I was mesmerized by making fast money and went into drug trafficking. As a result, it landed me in prison'.

\section{The evil violence tunnel}

The Evil Violence Tunnel Syndrome is characterized by intense and murderous rage directed to oneself or other. The introduction and discussion of this phenomenon in the group was received with enthusiasm. Group members recognize all symptoms of the syndrome and even admitted that: 'we live in this tunnel' (Figure 3). Inmates then engaged in an exercise to use their own words to describe the steps that lead someone to participate in impulsive violent acts. Discussing preventive measures for avoiding the tunnel also became a priority, once they realized that 'once you are deep in the tunnel, it is difficult to get out'.

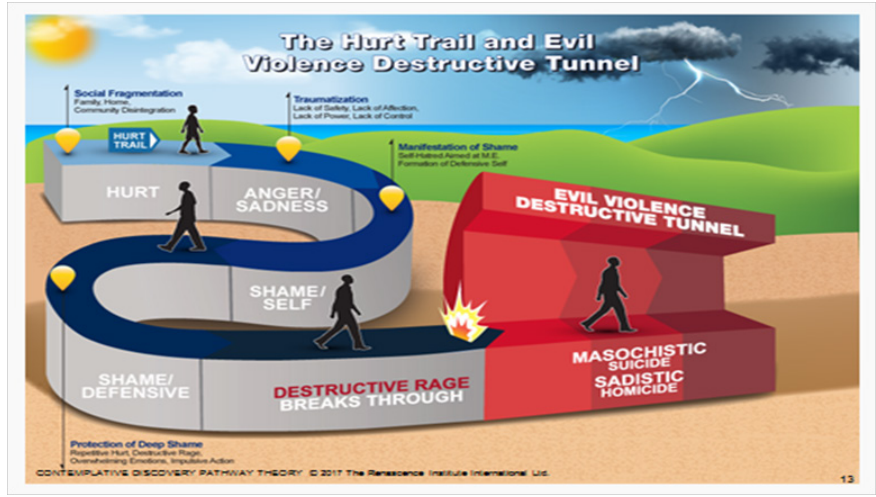

Figure 3 The Evil Violence Tunnel.

The stages of the Evil Violence Tunnel are: cognitive restriction, physiological arousal, emotional numbness, intense negative energy, ethical fragmentation and repetitive destructive behavior. After being taught the stages of the tunnel, the inmates decided to describe the stages in their own language. According to the inmates, the stages of the Evil Violence Tunnel are:

1. Fixation on the person who they wish to harm.

2. Physical and chemical reactions in their body destroy any kind of rational thinking.

3. The loss of feeling, especially fear.

4. They become overwhelmed by negativity and destruction and lose all sense of positive or compassionate feelings.

5. The breakdown of their value system where they do not consider or care about right and wrong regarding harming the person.

6. A continual path (pressure) to stab, shoot or strike the person without any awareness of the consequences. ${ }^{11}$

There are a staggering number of examples of group members sharing about committing acts of violence, but one of them stands out. For a brief period of time we had a few female inmates in our group. During one of these sessions, a lady shared her experience of being 'in the tunnel': 'I was raised by my grandmother and I knew all kinds of abuse growing up. When I was in my late 20's I was a single mother with a good enough job at a hotel. I started dating this policeman because I wanted to 'play him'. I wanted to make him believe I was carrying his child so he could take care of me and my children. As time went by, he started to become more and more violent and I started to hate him deeply. I even told him the child was not his. One day I was back from work and I was combing my hair while he was screaming at me, calling me names and threatening to rape me one more time. Suddenly I attacked him with the comb in my hand. To my horror the metal comb went all the way into his skull. The blood came pouring out and he died instantly. I still remember seeing my son cleaning the blood on the floor with the mop. I was in the newspaper and felt ashamed. I attempted suicide by setting the prison cell on fire. I am happy I survived because I realize now that 
my children and my mother are waiting for me to get out, so I have people I love and this keeps me going'.

\section{Resocialization-based themes}

Following violence, anger, revenge and addiction, the next most common themes were regret/guilt, relationships, hurt, hope/change and forgiveness. These themes appeared later in the group process, once group cohesion was established. Our facilitator, Mr. André Chappelle, initiated the discussion of these themes when he spoke freely about his painful experiences with family disputes, severe substance abuse, several incarcerations and homelessness. We laughed and cried with him as he told his authentic story. He stated: 'There were deep scars of abandonment, humiliation, and rejection that I had run from my whole life and would never have admitted to anyone. But in The Family, I began to open up by telling my story and sharing my fears. The beautiful thing was, this was met by love and it produced peace within my heart. I came to realize that our heart is like a sponge. It becomes filled with the hurt, fear and shame of a lifetime, often blocking love and hope, pushing our life towards despair. When we can squeeze the sponge to empty the hurt and shame by sharing our story in a caring environment like The Family, we make space for love to enter our hearts and peace soon follows. This peace I treasure and value and it acts like a barometer, for whenever I sense my inner stillness being ruffled, I check myself. I check myself because it's not what's happening on the outside that determines the state of my inner world, but rather it's the peace of God within me that allows me to determine how to respond. This is a choice: the choice to respond either from a heart of fear or a heart of love. You can either be a thermostat or a thermometer!'. ${ }^{10}$

Group members shared their reaction to seeing Mr. Chappelle homeless in contrast to seeing him fully rehabilitated. They congratulated and hugged him, saying, 'if you can do it, anyone can!"As the men shared their stories, the bond uniting the group became stronger. They said they were taking a risk in being emotionally vulnerable and warned us, 'if our family comes to visit and starts crying, we will tell them not to come back'. Most group members agreed and admitted that, 'Prison is no place for grieving. If we start thinking about our families, our wrongdoing and how we left them stranded without protection we will lose our minds'.

Below are excerpts from group sessions that centered on the themes of regret/guilt, relationships, hurt, hope/change and forgiveness:

\section{An example of regret/guilt and forgiveness}

An inmate said: 'I have been here for 31 years of life. I missed it all: my children growing up, my grandchildren being born, my parents' funerals and all graduations and weddings. I have survived all this anger and sorrow through Faith'. The group was respectfully silent as he spoke. Continuing, he said: 'I was bad since childhood. My father wasn't there, my mother had to work all the time and I was raised by my grandmother and other relatives. They never had a kind word of love or encouragement for me. I had to be out of their sight and do whatever they commanded. I was beaten often. I looked to my mother for comfort, but she beat me saying I should respect my relatives. At 7 years old after another bad beating, I decided to give up on love and my heart became cold. I enjoyed being bad, ran away and spent most of my time "on the blocks" where I was more appreciated. My criminal life started young'. The group asked him 'how his heart turned cold'. He said 'that is what happens when you believe you will never be loved'. He explained 'I always loved my mom and now I know she loved me. When I was sent to jail and given a long sentence she cried. I denied my wrongdoing and lied to her again. But after thinking about it-that's all we have to do in this place -I decided to change because I am a Christian. It took me two years to tell my mother the truth. If I could tell my mother the truth, maybe I could admit the truth to myself. I tried to reach out to the families of the victims to ask forgiveness. It took a long time before I could finally talk to them. Even though some did not forgive me, I had to ask because it made me feel better. But the most difficult thing was to forgive myself for the time I have lost with my children.'

\section{An example of hope/change}

Another inmate has been in prison for 25 years and is running a "toast master" programto help inmates learn to speak publicly. He is planning to create an association to provide guidance and support for discharged inmates.

\section{An example of hurt}

Group members admitted that having a loved one die while incarcerated is one of the most painful experiences. Feelings of regret and guilt are overwhelming. Crying is a sign of vulnerability and there is no private space to cry while incarcerated. We have heard stories of multiple losses in a short period of time. One inmate stated "I have lost eight people in the last two years. I now feel numb'.

\section{An example of relationships}

A participant who has not been in prison for a long time has a powerful influence on the group because he is a good listener. The men respect him very much and they are very grateful to him.

Another participant did not say very much, but when he shared his story, he spoke non-stop in describing his life. He admitted being a drug addict who had spent many years being zoned out. Because of this, he was an absent father for his two daughters. He described being stabbed and nearly died. But he nurse caring for him was an angel and motivated him to recover. He was inspired by Maya Angelou's poem 'Why the Caged Bird Sings' and said 'we now have a bird that visits us in the cell. We feed him and call him Freedom. 'Recently, he has shown definite signs of resocialization. He described a situation where he was physically challenged and wanted to seek revenge. He said he held back because he did not want to disappoint the Family group.

\section{Signs of resocialization in group process}

The following are some examples of the emerging Resocialization process occurring in the group.

1. The increased ability to delay gratification and have better impulse control:

a) The men ask to leave the group when they are angry so they can cool down and return to continue the discussion. This means they are moving from a purely instinctive reaction to a thought out response to the situation;

b) We notice now that the men wait to talk to each other and often ask a week in advance to speak at the next meeting;

c) They can now have a discussion without getting angry and threatening because they have learned to communicate with each other. For example, they say "I am just talking about myself" or they admit "we can agree to disagree". 
2. The men make less generalizations in the group, e.g. originally they would make broad statements such as "all men cheat". Now they take personal responsibility and are willing to say "I admit that I cheat, but it does not mean that all men do as I do".

3. The men have developed better conflict resolution skills and are able to have more harmonious conversations and effective communication. They speak slower and have less threatening outbursts when the group does not agree with them. They are more respectful to us the facilitators and to each other. For example, because they are interested in participating, they would ask beforehand if they could lead the meditation.

4. As the group has developed, the men are able to express vulnerability by sharing intimate, personal and emotional stories. As a result, they are more open to being emotionally labile or even crying.

5. The group has expressed a deep gratitude to us for starting the Family group in the prison. For example, at Christmas, they planned a special ceremony to thank us for our interest and work. We have also noticed that at the end of each group, many of the men come up to us and say "thank you" before returning to their cells.

6. As the group has developed, the men are more open in describing their artistic expression, particularly as it relates to music, prayer, poetry etc.

7. The men have become more self-reflective and are able to share their inner feelings more openly, e.g. they can express painful feelings such as depression, sadness or anger.

8. Developing better impulse control, the men are less reactive and revengeful, creating more harmonious relationships among themselves.

9. The men have a deep emotional investment in the group and have taken ownership and personal responsibility by naming the group the "free your mind group". They also invite others to the group and share the information they learn with family and friends. They are very excited about attending the group and claim they can't wait for the time to come for the group to take place. They also say they make special preparation to come to the group, e.g. shaving and appearing neat. This illustrates the development of a deeper sense of self-care and increased self-esteem.

10. As the group developed, the concept of forgiveness instead of revenge has emerged as a major theme. They are beginning to understand that forgiveness is the only process that can heal a wound of the past that cannot be changed.

11.Most exciting is that the men have become more hopeful about their life. According to them, they can't wait to return to the community and live a more simple life by helping others.

\section{Conclusion}

The Family Prison Group was developed to create a safe space for traumatized, incarcerated persons to work through their shame and pain. The participants have accepted the mantra of The Family 'jaw, jaw stops war, war'. They are learning that in sharing their personal stories and accepting responsibility for their actions, they experience a deeper sense of freedom. The Family Program aims to enhance Resocialization by helping persons to become familiar with their inner life. As they become more self-reflective and share their personal stories, they develop powerful bonds of connection, enhancing the development of caring community.

The thematic analysis of the Prison group, described in this paper indicates the depths of negativity of shame but also provides hope for Resocialization and preparation for the inmates to live a meaningful and crime-free life upon their release. Our hope is that this group process intervention could increase its positive effect for marginalized populations inside and outside the prison walls. We realize this is just a start, but we are encouraged by the results of the group and are planning to start a group for the female inmates in the future. Hopefully, this will lead us to develop a group for discharged inmates giving us a full spectrum of services for the inmates in prison and also when they are released into the community. It is important for all of us to realize that the inmates in prison will someday return to live in the community. Thus, the better we prepare them for successful reentry into society, the more effective our law-enforcement program.

\section{Acknowledgements}

None.

\section{Conflict of interest}

The author declares no conflict of interest.

\section{References}

1. Allen. Report on Crime. 2013.

2. Jekel JF, Allen DF, Podlewski H, et al. Epidemic, free-base cocaine abuse: Case study from The Bahamas. Lancet. 1986;1(8479):459-462.

3. Goffman E. Characteristics of total institutions. USA: Holt, Rinehart and Winston; 1961. p. 312-338.

4. Allen DF, Mayo M, Allen Carroll M, et al. Cultivating Gratitude Contemplative Discovery Pathway Theory Applied to Group Theory in The Bahamas. Journal of Trauma \& Treatment. 2014:7.

5. Institute for Criminal Policy Research. World Prison Brief. UK: Birkbeck University of London; 2016.

6. Allen DF, Allen Carroll M, Bethell KY, et al. An Instrument for Assessment of Longitudinal Community Resocialization Through a Group Process Intervention. J Trauma and Treat. 2017;6:355.

7. Frankl VE. Man's Search for Meaning. USA: Beacon Press; 1946.

8. Allen DF. Shame: The Human Nemesis. USA: Eleuthera Publications; 2010.

9. David Foster Wallace's. Commencement address at Kenyon College published in The Economist Magazine in September 19 $9^{\text {th }} 2008$. USA; 2005.

10. Allen D, Bethell K, Allen Carroll M. Anger and Social Fragmentation: Evil Violence Tunnel. Journal of Psychotherapy Integration. 2017;27(1):79-92.

11. Allen DF. The war for Peace Within Ourselves: By André Chappelle. EC Psychology and Psychiatry. 2017;1.6(2017):226-232. 